\title{
Rats' location during conditioned suppression training
}

\author{
RICK A. BEVINS and JOHN J. B. AYRES \\ University of Massachusetts, Amherst, Massachusetts
}

\begin{abstract}
Freezing is often cited as the interfering behavior responsible for barpress conditioned suppression. However, auditory cues that precede shock can evoke more freezing than can visual cues despite producing similar suppression. In two experiments, we sought to resolve this paradox by measuring rats' location in the box in addition to recording freezing during conditionedsuppression training to tones and lights. Tone evoked more freezing than light but similar suppression. During both cues, rats left the bar and dipper areas and moved to the lower middle and rear of the box. When the bar was then removed and the dipper entry sealed, the preference for the middle and rear of the box disappeared. Apparently, frightened rats do not simply prefer the middle and rear of our box. The fact that rats leave the bar and dipper areas equally during both auditory and visual cues explains how the two cues can foster similar suppression despite evoking different levels of freezing. But the fact that rats leave the bar and dipper areas at all remains to be explained.
\end{abstract}

Since its development by Estes and Skinner (1941), the barpress conditioned-suppression procedure in rats has become a popular tool for the study of Pavlovian conditioning. Despite its popularity, though, it has not escaped criticism. One complaint is that conditioned suppression is a measure of what rats are not doing rather than what they are doing. Workers often assume that suppression is produced by some defensive behavior that competes with barpressing. Freezing is often cited as the interfering behavior, and, indeed, it has been shown that freezing and barpress suppression are highly correlated (Ayres \& Vigorito, 1984; Bouton \& Bolles, 1980). It has also been shown, however, that auditory cues can evoke much more freezing than can visual cues even though both evoke similar barpress suppression (Ayres, Axelrod, Mercker, Muchnik, \& Vigorito, 1985; Bevins \& Ayres, in press). This discrepancy is paradoxical if freezing is truly the interfering behavior. In the present experiments, we hoped to resolve this paradox by recording freezing, barpress suppression, and rats' location in the box when tone and light conditioned stimuli (CSs) preceded shock. To record location, we divided the box into cells and used a timesampling procedure to estimate the time spent in each cell during CS and pre-CS periods.

This research was supported by Grant BNS 87-22173 from the National Science Foundation to John J. B. Ayres. We thank Melody Albert, John Donahoe, and Gordon Wyse for their guidance and Mark Bouton for his comments on the manuscript. We also thank D. J. Creations and Wendy Bevins for preparation of the figures. Correspondence may be addressed to John J. B. Ayres, Middlesex House, Department of Psychology, University of Massachusetts, Amherst, MA 01003.

\section{EXPERIMENT 1}

\section{Method}

\section{Subjects}

Sixteen male albino rats, 90 days old on arrival from the Holtzman Company, Madison, WI, were housed individually in suspended stainless steel cages in a room lighted $24 \mathrm{~h} /$ day. Previously the rats had served in a study of the effects of light preexposure on the acquisition and extinction of conditioned suppression to a light CS. While deprived to $80 \%$ of their free-feeding weights, the rats had received CS trials while barpressing for $32 \%$ liquid sucrose given on a variable-interval (VI) 1-min schedule of reinforcement with a variable-time 1 -min limited hold. At the end of that work, the groups were still showing similar, moderate suppression to the light. The rats then stayed in the colony at $80 \%$ body weight for 17 days. When the present study began, the rats were 150 days old and continued to be kept at $80 \%$ body weight.

\section{Apparatus}

Four Gerbrands operant boxes were housed in ventilated $.61-\mathrm{m}$ cubes of $12.7-\mathrm{mm}$ plywood lined with acoustical tile. Each cube had a double-paned Plexiglas door, which allowed full view of the rats yet preserved sound attenuation. Outside and above the cubes and out of the rats' line of sight were mounted a relay and some 28-V indicator lamps. These devices paced the scoring of freezing and location by cycling on for $1.4 \mathrm{sec}$ then off for .1 $\mathrm{sec}$ throughout each session.

The inside dimensions of each box were $23.2 \times 20.3 \times 19.5 \mathrm{~cm}$. Each floor was made of 18 stainless steel rods, $2 \mathrm{~mm}$ in diameter, spaced $1.3 \mathrm{~cm}$ apart center to center. The end walls were aluminum. The side walls and lid were clear Plexiglas. Centered in one end wall was a standard Gerbrands bar, $5 \times 1.5 \mathrm{~cm}$, mounted $8 \mathrm{~cm}$ above the floor. In the lower left corner of this wall was a $5 \times 5 \times 5.5 \mathrm{~cm}$ recessed dipper tray. A cue light, $2.5 \mathrm{~cm}$ in diameter, not used here, was centered $3.25 \mathrm{~cm}$ above the dipper entry. To the rat's left as it faced the bar was the Plexiglas side wall closest to the observer. Thin black tape divided that side wall into six cells, each about $7.7 \mathrm{~cm}$ wide and $10.1 \mathrm{~cm}$ high. From left to right, the top cells were numbered 1,2 , and 3 , and the bottom cells, 4,5 , and 6 . The dipper 
tray was Cell 0 . The bar was just below the line between Cells 1 and 4. Rats usually barpressed with their noses at bar level, so barpressing usually occurred in Cell 4.

On each box lid were two $10-\mathrm{cm}$-diameter speakers. One provided a $1000-\mathrm{Hz}$ tone CS of $86 \mathrm{~dB}$. The other was not used. Sound intensity was measured with a General Radio Model 1565-B soundlevel meter set on the Cs scale with the microphone about $7 \mathrm{~cm}$ from the dipper tray. A light CS was provided by a 110-V, 7.5-W white frosted bulb. Background lighting was provided by a similar red frosted bulb. The bulbs were mounted roughly at bar level on the rear wall of each housing cube $15 \mathrm{~cm}$ from the Plexiglas wall to the rat's right as it faced the bar. With the selenium cell of a Pasco Scientific photometer (Model 9152) centered at bar level on the opposite Plexiglas wall, the red bulb alone produced a reading of $2 \mathrm{~lx}$. Both bulbs together yielded $17 \mathrm{~lx}$. Scrambled grid shocks (.8 mA for $1 \mathrm{sec}$ ) served as unconditioned stimuli (USs). They were provided by four Grason-Stadler shock sources (Model E1064GS). Barpressing, the response to be suppressed by CSs, was maintained with 4-sec deliveries of a .1-ml dipper cup of $32 \%$ liquid sucrose.

\section{Procedure}

The rats were placed immediately on the already familiar VI 1-min schedule of reinforcement. One 1-h VI session was given daily for 6 days. Each contained one 2-min tone (T), one 2-min light (L), and two .8-mA 1-sec grid-shock USs. For Group $P(n=12)$, each CS coterminated with a US. For Group EU $(n=4)$, CSs and USs were explicitly unpaired. For both groups, $T$ began at the start of Min 20,36, and 16 on Days 1,2, and 3, respectively, and $L$ began at the start of Min 50,10, and 42. For Group EU, shocks occurred at the end of Min 30 and 40 on Day 1,20 and 50 on Day 2, and 6 and 32 on Day 3. On Days 4, 5, and 6, the procedures of Days 1,2 , and 3 were repeated.

Direct observations. On odd days of conditioning, freezing during both CSs was scored for half the rats and location was scored for the other half. On even days, the scoring was reversed. Thus, for every 2 days, one freezing measure and one location measure were obtained for each rat to each CS. Both measures were obtained using a time-sampling procedure (Bouton \& Bolles, 1980; Fanselow \& Bolles, 1979; Sigmundi, Bouton, \& Bolles, 1980). For $5 \mathrm{sec}$ before the start of the 2-min pre-CS period, nine of the indicator lamps above the housing cubes lit up to alert the observer. At the end of this cue, the observer scored the behavior of the first rat and then, paced by the relay clicks and two flashing indicator lamps, scored each of the three remaining rats in turn. There were 10 observations per rat per minute. The relay clicks and flashing pacing lamps were always present throughout all sessions so that they could not foreshadow CSs even if they were somehow detected by the rats. For the freezing measure, each observation was scored as either "freezing" or "not freezing." Freezing was defined as the absence of any movement except that of the rat's sides required for breathing. Not freezing was defined as anything else. When freezing was recorded, each rat was given a percent freezing score. That score was simply the percentage of the 20 observations during a CS or pre-CS period that were scored as freezing. When location was scored, each observation was given a number from 0 to 6 corresponding to the cell in which the rat's nose was seen. From these scores, an estimate of the percentage of the time spent in the different areas of the box for each rat was obtained by dividing the number of observations in a given cell by the total number of observations made for that rat. The first author observed the rats in this way for the entire study. Beforehand, we practiced scoring location with four extra rats and agreed on $81 \%$ of the 200 observations we scored in common. Agreement on freezing in this laboratory is usually over $90 \%$ (e.g., Bevins \& Ayres, in press).

Barpress suppression was expressed as a ratio formed by dividing the number of responses during the 2-min CS by the sum of that number plus the number in the 2-min pre-CS period (Annau \& Kamin, 1961). With this ratio, a score of .5 denotes no effect of the CS and a score of 0 denotes total suppression during the CS.

Between- and within-group contrasts were performed using $t$ tests and correlated $t$ tests, respectively. All tests used a two-tailed rejection region of .05 .

\section{Results}

For both groups, no freezing occurred during pre-CS periods, and none occurred during either CS for Group EU. The lower half of Figure 1 shows the acquisition of freezing for Group P. Recall that an alternating method of data collection had to be used to obtain both freezing and location data. Thus the "early" measure of freezing was taken from half the rats on Day 1 and from the remaining rats on Day 2. The same is true for location. Such alternated scoring continued throughout. Thus the "middle" measure consists of data from Days 3 and 4, and the "late" measure consists of data from Days 5 and 6. Early in conditioning, there was little freezing to either CS, but freezing increased with training to both CSs, especially $T$. Late in training, $T$ evoked significantly more freezing than did $L[t(11)=5.25]$.

The upper half of Figure 1 shows the acquisition of barpress suppression. For Group P, that suppression increased with training to both CSs. Because of the rats' past history with $L, L$ evoked more suppression than did $T$ on the early measure. For Group P alone, this difference closely approached significance $[t(11)=2.195, p=.0505]$. Moreover, for Groups P and EU combined, the difference was significant $[t(15)=3.42]$. On the late measure for Group $P$, there was no significant difference in suppression to $\mathrm{T}$ and $\mathrm{L}$. For Group EU, suppression to both CSs decreased with training. Though $\mathrm{L}$ tended to evoke more suppression throughout the study for Group EU (presumably because of the rats' prior history of conditioning to $\mathrm{L}$ ), suppression to $\mathrm{T}$ and $\mathrm{L}$ did not differ significantly on the late measure. There, Group P suppressed significantly more to each CS than did Group EU [ $t s(14)>3.98]$.

Figure 2 shows the percentage of time that Group $P$ spent in various areas of the box during conditioning. The figure shows the two-dimensional view of the box (not to scale) as seen by the observer. Cell 0 represents the dipper tray. Cells 1 and 4 denote the top and bottom halves, respectively, of the front third of the box (close to the bar). The bar is in Cell 4. Cells 3 and 6 represent the top and bottom halves, respectively, of the back third of the box (away from the bar). The dotted curves depict location during pre-CS periods. The solid curves show location during CSs. As can be seen, the rats spent little time with their noses in the upper cells $(1,2$, and 3$)$. L, however, did evoke a small increase in the time spent in Cell 1. Thus, there seemed to be some rearing to $L$ in the cell above the bar (if rearing is defined as raising the nose at least $10.1 \mathrm{~cm}$ from the floor). (Note that the rats are tall enough to touch their noses to the top of the upper cells. Indeed, such behavior is often seen to novel CSs.) Also, as conditioning proceeded, the rats showed 


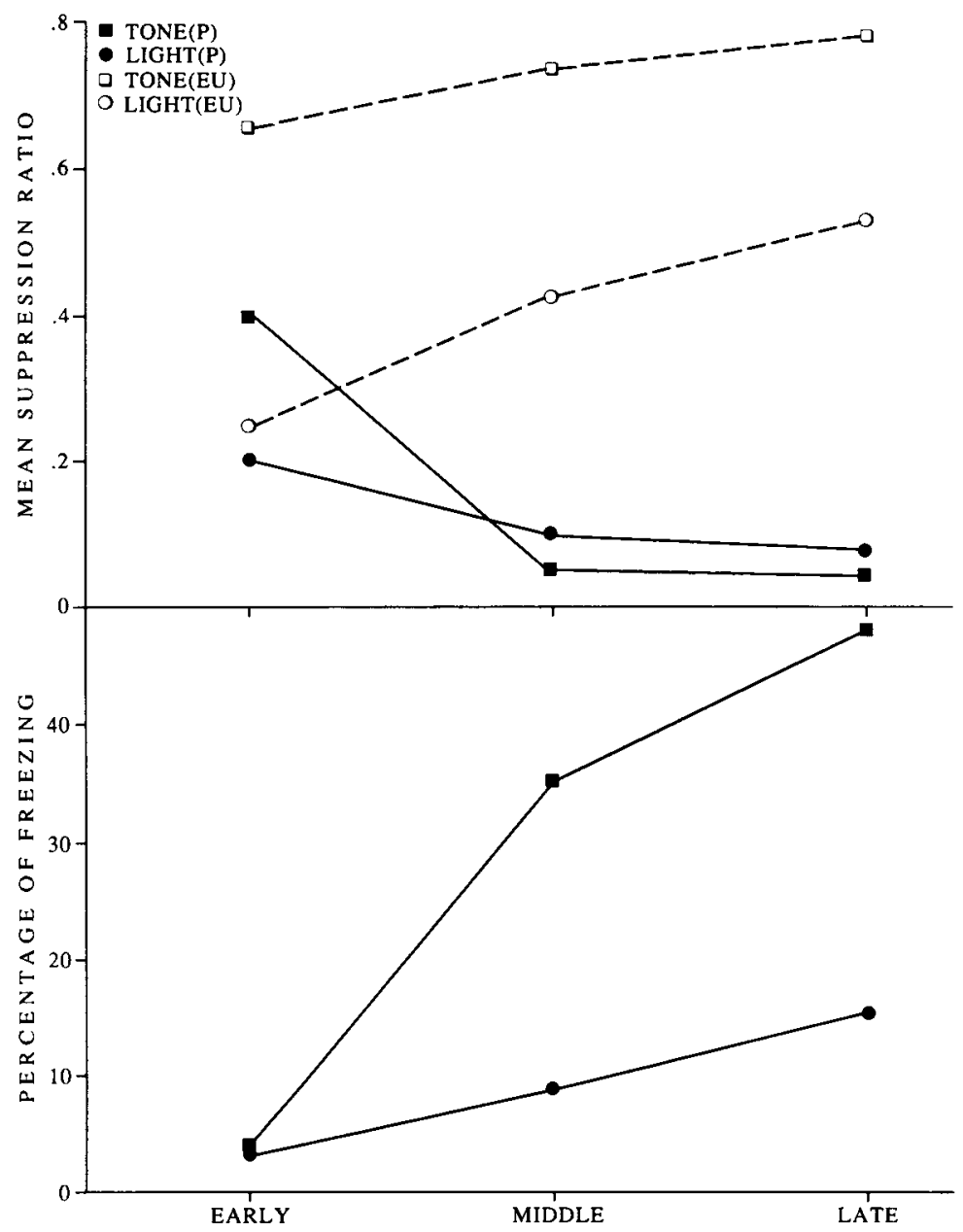

Figure 1. Barpress suppression (top panel) and freezing (bottom panel) to each CS during conditioning in Experiment 1.

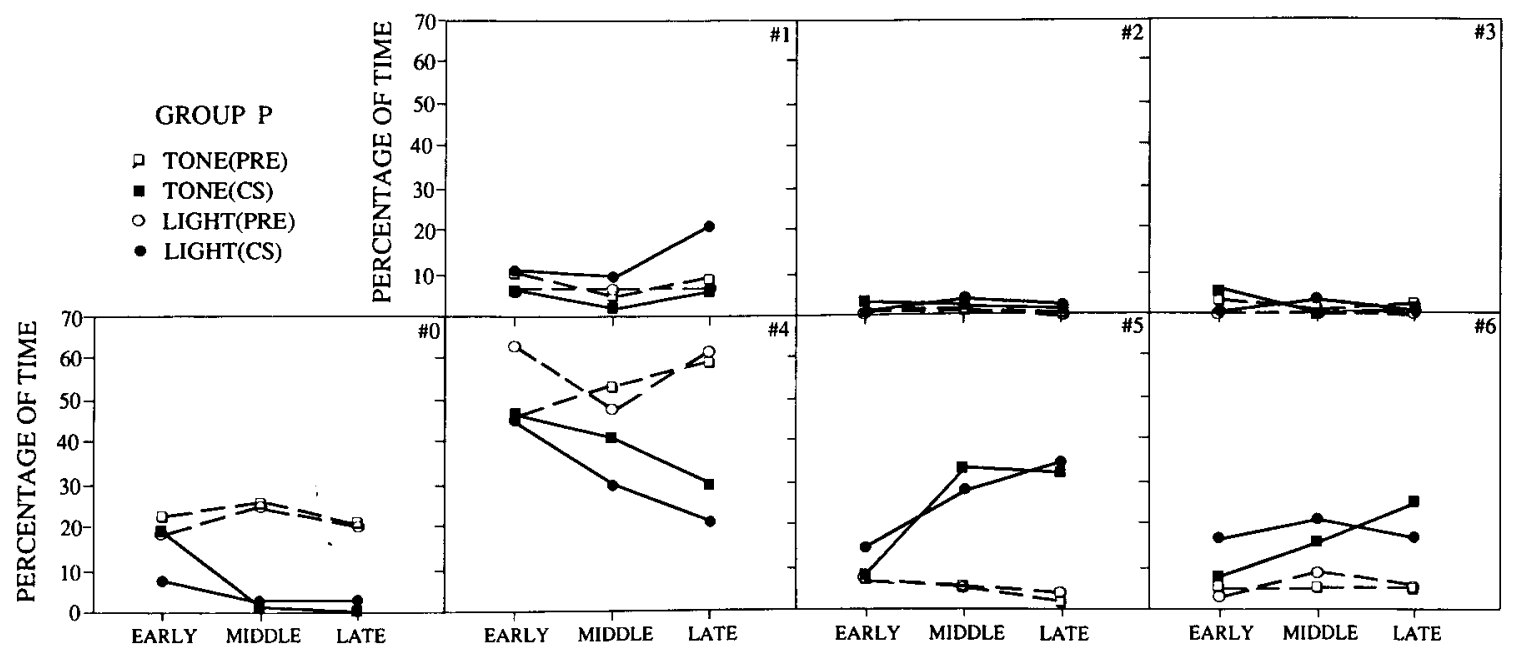

Figure 2. Time spent in given areas of the box (denoted by the number in the upper-right corner of each cell) during conditioning in Experiment 1 for Group P. The figure is a two-dimensional view of the box as seen by the observer. The bar is in Cell 4. The dipper tray is Cell 0 . 
no systematic changes in the time spent in any cell during pre-CS periods. During the CSs, however, time spent in Cells 0 and 4 declined with training and the time spent in Cells 5 and 6 increased accordingly. In short, the rats moved out of the bar and dipper area during both CSs.

Statistical analyses confirmed these impressions. On the late measure, the rats spent less time in Cells 0 and 4 during CSs than they did during pre-CS periods $[t \mathrm{~s}(11)>$ 5.94]. Similarly, during CSs, they spent more time in Cells 5 and 6 than they did during pre-CS periods $[t s(11)>2.99]$. On the late measure of location, no difference between $\mathrm{T}$ and $\mathrm{L}$ was found in any cell other than Cell $1[\operatorname{ts}(11)<2.15]$. On that measure, the rats spent more time in Cell 1 during $L$ than during either the corresponding pre-CS period or during $\mathrm{T}$ [ $t \mathrm{~s}(11)>2.25$ ].

Location for Group EU is not shown. Like Group P, Group EU spent very little time in the upper cells and showed no systematic changes in location in pre-CS periods over the course of training. Unlike Group P, Group EU also showed no systematic changes in location with training during either CS. Moreover, late in training, there were no significant differences between either CS and its respective pre-CS period in any cell llargest $t(3)=3.06]$.

\section{Discussion}

Because $\mathrm{L}$ had been moderately conditioned in a prior study, it produced, on the early measure of conditioning, more barpress suppression than did $T$. Yet freezing to $\mathrm{L}$ and $T$ was virtually identical. It appears that barpress suppression was more sensitive to the initial difference in the associative value of the two CSs than was freezing.

Our suppression and freezing data replicated past results (Ayres et al., 1985; Bevins \& Ayres, in press). Thus, at the end of training, $T$ evoked more freezing than did $L$ even though the two CSs evoked similar levels of barpress suppression. This similarity in suppression to $L$ and $T$ is probably not due to a floor effect. Bevins and Ayres (in press) found levels of suppression to $T$ and $L$ resembling those depicted here in Figures 1 and 3. However, they also found that $\mathrm{T}$ and $\mathrm{L}$ in compound evoked more suppression than did either element alone. Thus there was room for the elements to show stronger suppression. Freezing and barpress suppression did not increase with training for Group EU. Therefore, the pairing of CS and US was responsible for the increases in those measures that occurred with training in Group P.

The location data seem to resolve the paradox that auditory and visual CSs can evoke different levels of freezing yet produce similar barpress suppression. Thus, the auditory and visual CSs similarly reduce the time spent in the bar and dipper areas, and this reduction is accompanied by similar barpress suppression.

The changes in location do not seem to be due to withdrawal from the CSs (Karpicke, Christoph, Peterson, \& Hearst, 1977). The speaker for $T$ was above Cells 5 and 6. Therefore, if the rats were withdrawing from $T$, time spent during $T$ should have increased in Cells 4 and 0 and decreased in Cells 5 and 6 . Likewise, $L$ was closer to Cell 5 than to Cells 0,4 , and 6 . If the rats were withdrawing from $L$, time spent during $L$ should have increased in Cells 0, 4, and 6 and decreased in Cell 5. Neither outcome occurred. Although Karpicke et al. found evidence for withdrawal from CSs and we did not, our results should not be viewed as inconsistent with theirs. They used CSs that, unlike ours, were deliberately made to be highly localizable.

The lack of systematic changes in location for either CS or pre-CS periods in Group EU clearly demonstrates that the changes in location with training for Group $P$ are not unconditional effects of unpaired CSs or USs. Therefore, we conclude that the changes in location with training for Group $P$ are associative and thus that they can provide a measure of an aversive CS's conditioned value.

Speculating about why the rat learns to leave the bar and dipper areas during aversive CSs, we might offer the following possibilities; (1) The bar and dipper evoke behaviors (barpressing and eating) that compete with preparatory responses specific to shock. Avoiding these stimuli during CSs is thus reinforced by some reduction in US effectiveness. (2) The bar and dipper become aversive during CSs because the rat is likely to be focused on them at the time of shock onset (cf. Bolles, Holtz, Dunn, \& Hill, 1980). (3) Shock at the end of the CS constitutes discriminated adventitious punishment of the behavior of being in the bar and dipper areas (cf. Bolles et al., 1980). As training continues, the rat learns to "passively avoid" these punished behaviors by staying in other parts of the box. (4) The frightened rat prefers a specific location in the box, which by chance in our apparatus happens to be the lower middle and rear of the box. This preference is unrelated to preparatory responses or to any presumed aversiveness of the bar and dipper during the CS or to any presumed discriminated adventitious punishment. Experiment 2 provides a preliminary assessment of these hypotheses.

\section{EXPERMMENT 2}

Experiment 2 sought to replicate with naive rats some of the results of Experiment 1. At the end of the replication, a new, off-line, conditioning phase was added. Here, fear conditioning was continued but without the bar and dipper. If rats leave the bar and dipper area during CSs because the bar and dipper evoke behaviors that compete with preparatory responses specific to shock or because the bar and dipper become aversive during the CS, then removing the bar and dipper should reduce the rats' tendency to go toward the back of the box during CSs. If, on the other hand, the frightened rat prefers the back of the box for some other reason, then removing the bar and dipper cues should not reduce the time spent in the back of the box during CSs.

The added off-line phase also provided an opportunity to clarify an observation made by Ayres et al. (1985). These authors found more freezing both during and be- 
fore CSs in rats trained off line than in rats trained on line. Indeed, pre-CS freezing in their off-line rats was so great as to obscure stimulus control by the CSs, especially their light CS. Ayres et al. offered a variety of explanations for the generally greater freezing during off-line training. One explanation was simply that in the off-line procedure, there was no barpressing or eating to compete with freezing. Other explanations that were offered assumed that the off-line procedure fostered superior conditioning. These latter explanations differed among themselves only in the mechanism they held responsible for that superiority. On the basis of the findings of Ayres et al., the shift from on-line to off-line training in the present study would be expected to increase freezing. The rapidity of that increase should help us decide between the two classes of explanation for greater freezing off line. A gradual increase would support the view that off-line training yields superior conditioning. But if the increase occurs immediately, even before the first US is given off line, then the increase would appear to reflect the absence of competing barpress and consummatory responses.

\section{Method}

\section{Subjects}

Sixteen naive male albino Holtzman rats, 90 days old on arrival, were acclimated to the colony for a week. Then, over the next week they were reduced to $80 \%$ of their free-feeding weights, where they were kept throughout the study.

\section{Apparatus}

The apparatus was unchanged except during off-line training. There, the bar was removed, and the bar slot and dipper entry were covered with metal plates.

\section{Procedure}

Preliminary training. The rats were assigned randomly to Groups $P$ and $\mathrm{EU}(n \mathrm{~s}=8)$. They then received 1 day of magazine training, 1 day of barpress shaping, 2 days of training in which each of roughly 90 barpresses was reinforced, and 5 days of training on the VI schedule of Experiment 1. VI training and all later sessions were $1 \mathrm{~h}$ long. When the bar was in the box, the VI schedule was in force.

On-line conditioning. The procedure for on-line conditioning was that of Experiment 1 except that training lasted 8 days rather than 6 .

Off-line conditioning. Following on-line conditioning were 6 days in which T, L, and shock were given to each group as in on-line conditioning except that the bar was removed and the bar slot and dipper entry were sealed with metal plates.

Location and freezing were scored as in Experiment 1.

\section{Results and Discussion}

The lower half of Figure 3 shows the acquisition of freezing during on-line conditioning. ${ }^{1}$ The alternating method of data collection described in Experiment 1 was used to obtain the "early," "middle 1 ," "middle 2," and "late" measures of freezing and location. For Group $P$, there was initially little freezing to either CS. However, freezing increased with training to both CSs, especially $T$. Late in training, Group $P$ froze more to $T$ than to $L[t(7)=3.76]$ and froze more to both CSs than did Group EU [ $t s(14)>3.92]$. Group P did not freeze at all during pre-CS periods. Group EU froze little to either CS, but its freezing in pre-CS periods increased with training. Late in training, Group EU froze more in the pre-CS period than during either $T$ or $L[t s(7)>2.91]$.

The upper half of Figure 3 shows the acquisition of barpress suppression during on-line conditioning. For Group P, barpress suppression was initially weak and was the same to $T$ and $L$. This similarity of initial suppression to $T$ and $L$ in these naive rats contrasts with the stronger suppression to $L$ in Experiment 1 (upper half of Figure 1). This contrast is consistent with the conclusion drawn earlier that the initially strong suppression to $L$ in Experiment 1 reflected a preexperimental conditioning history and therefore that the difference in suppression to $\mathrm{T}$ and $\mathrm{L}$ in Experiment 1 reflected the different associative values of those CSs. As training continued in the present experiment, suppression increased to both CSs in Group P and decreased to both CSs in Group EU. Late in training, suppression to $\mathrm{T}$ and $\mathrm{L}$ did not differ in either group. Suppression to each CS in Group P was significantly greater than that to the same CS in Group EU $[t \mathrm{~s}(14)>4.7]$.

Figure 4 shows Group P's location during on-line training. As in Experiment 1, the rats spent little time in the upper cells. In the lower cells, where they spent most of their time, the time spent during CS and pre-CS periods was similar early in conditioning but differed late in conditioning. Specifically, on the late measure, rats spent less time in Cells 0 and 4 during CS periods than during preCS periods, but in Cells 5 and 6, the reverse was true.

Statistical analyses were performed to test these impressions. On the late measure, significantly less time was spent in Cell 0 during $T$ and $L$ (combined) than during $\mathrm{T}$ and $\mathrm{L}$ pre-CS periods (combined) $[t(7)=3.57$ ). In Cell 4 , this trend only approached significance $[t(7)=$ $1.91, p<.10$ ]. Conversely, in each of Cells 5 and 6 , the opposite trends were significant $[t \mathrm{~s}(7)>3.0]$. On the late measure, no difference between $T$ and $L$ was found in any cell other than Cell $5[t(7)=2.65]$.

Location for Group EU is not shown. Like Group P, Group EU spent very little time in the upper cells. Unlike Group P, however, Group EU did not reduce its stay in the dipper area or increase its stay in the lower middle or rear of the box during CSs. Moreover, late in training, there were no systematic changes in location during pre-CS periods and no statistically significant differences in location between either CS and its respective pre-CS period in any cell $[t \mathrm{~s}(7)<1.45]$.

So far, the data presented replicate with naive rats the major results of Experiment 1. Thus, in Group P, we once again found evidence for greater freezing to $T$ than to $L$ late in training despite similar barpress suppression, and we found that the rats tended to leave the bar and dipper area and move toward the middle and rear of the box during CSs. All of these results appeared to be associative as they did not occur in Group EU.

Some of the results of the new phase of the experiment, the off-line conditioning phase, are displayed in Figure 5. 


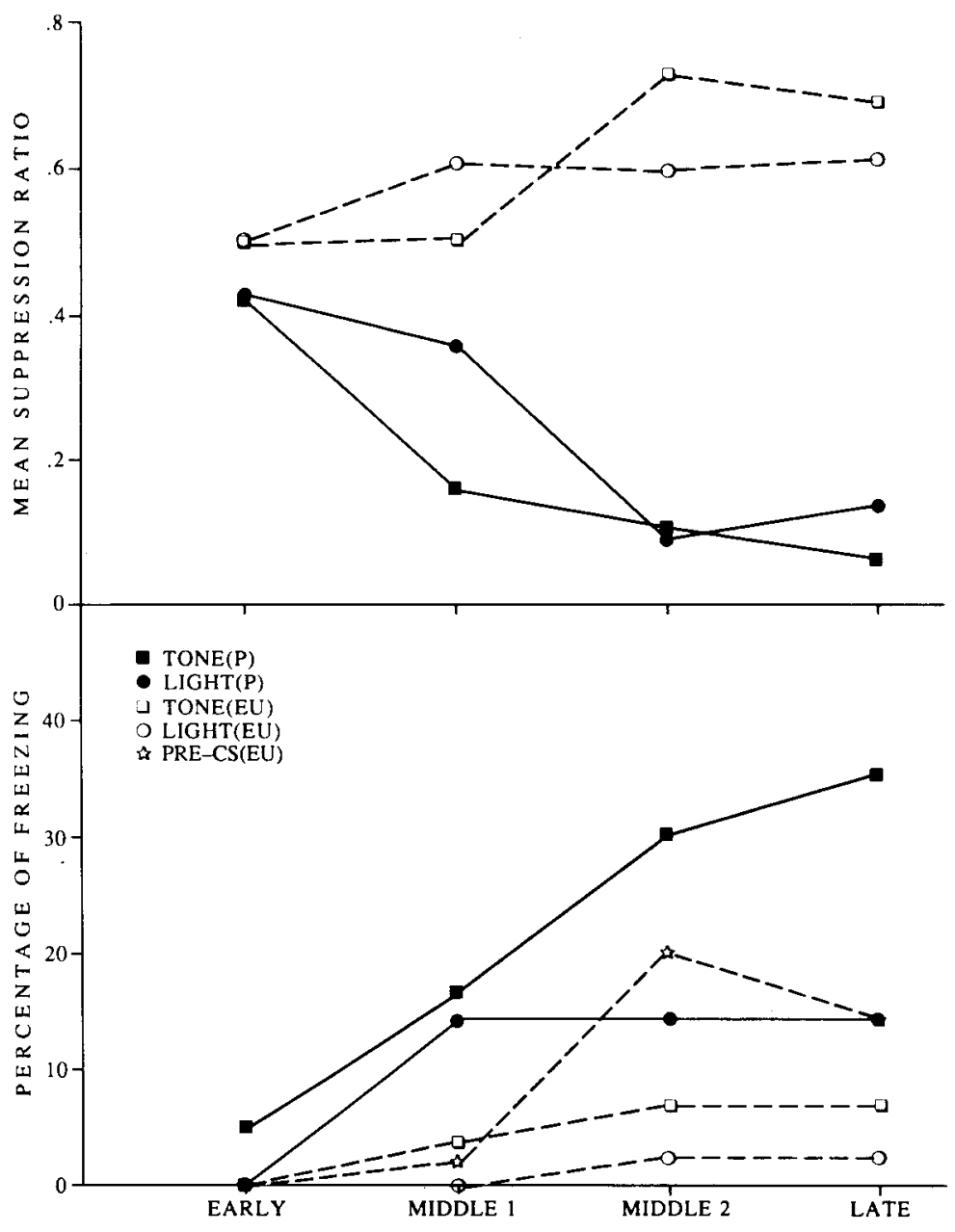

Figure 3. Barpress suppression (top panel) and freezing (bottom panel) to each $\mathrm{CS}$ for Groups $P$ and EU during on-line conditioning in Experiment 2.

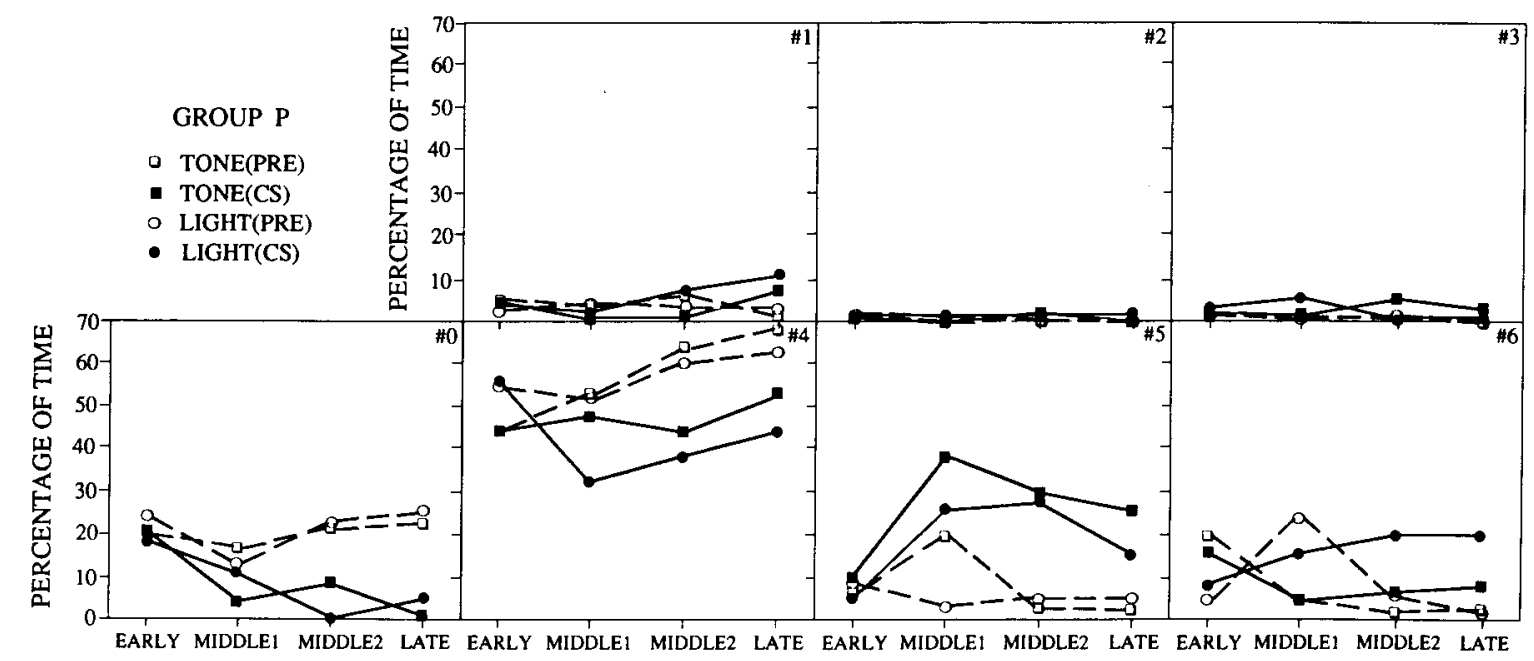

Figure 4. Time spent in given areas of the box during on-line conditioning in Experiment 2 for Group P. 


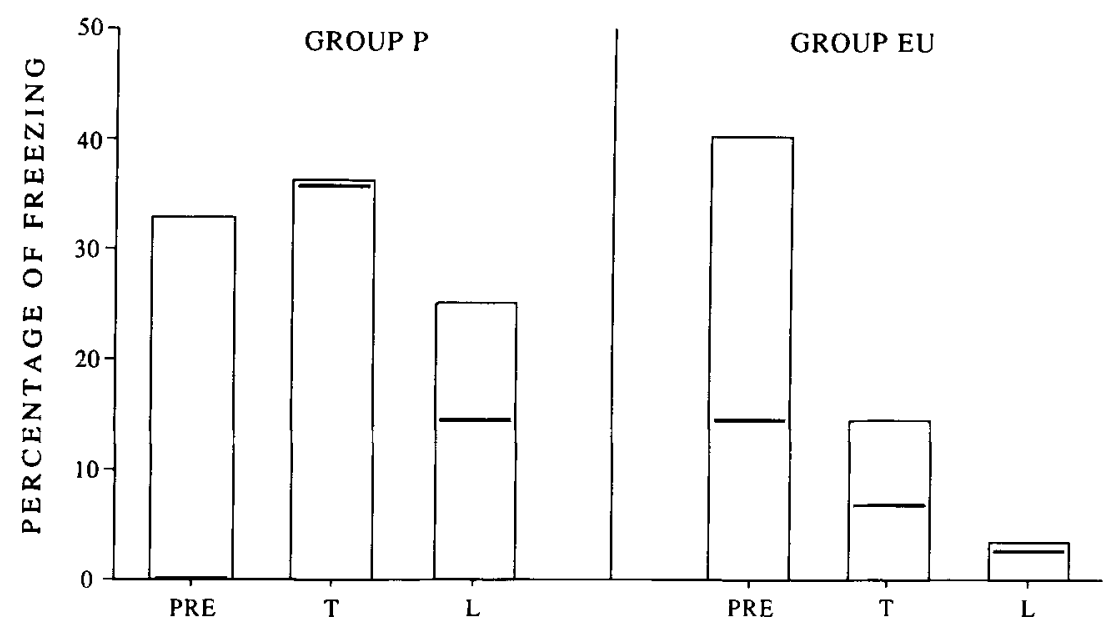

Figure 5. Freezing for Groups $P$ (left panel) and EU (right panel) during the late measure of off-line conditioning in Experiment 2. Thick horizontal lines denote freezing on the late measure of on-line conditioning.

The figure shows the late measure of off-line freezing. For comparison purposes, the thick horizontal line in each bar denotes the level of freezing obtained for the late measure during on-line conditioning. For Group P, the shift from on-line to off-line training produced an increase in pre-CS freezing and freezing to L. Indeed, pre-CS freezing increased so much as to obscure stimulus control by the CSs, particularly $L$. These results are entirely consistent with those of Ayres et al. (1985). However, freezing to $\mathrm{T}$ did not increase much, and this seems inconsistent with the results that Ayres et al. found with white noise.

We can now ask whether the increase in pre-CS freezing and freezing to L occurred gradually during the course of off-line training or whether it occurred immediately following the shift to the off-line condition. To answer this question, we compared the percentage of freezing on the last day of on-line training with that on the first day of off-line training (data not shown in the figure). Because of the alternating method of data collection, data for only four rats could be compared. For on-line conditioning, no pre-CS freezing was observed. However, on the first day of off-line conditioning, mean pre-CS freezing for these four rats increased to $57 \%$ prior to the first CS trial. A similar increase in freezing was also observed for $T$ and $L$. For the last day of on-line conditioning, freezing to $\mathrm{T}$ was $43 \%$ and freezing to $\mathrm{L}$ was $10 \%$. Freezing increased on the first day of off-line conditioning to $56 \%$ for $T$ and $36 \%$ for $L$. Thus the change to off-line conditioning immediately increased both pre-CS and CS freezing. The immediacy of the increases in freezing argues against the idea that freezing is greater off line because of mechanisms that favor conditioning in the off-line procedure. The increases occurred prior to the first US given off-line. Instead, the data suggest that freezing increased simply because competing responses, barpressing and eating, were removed in the off-line procedure. It might also be argued that the sudden increase in freezing reflected the removal of appetitive emotional states that might compete with fear (e.g., Estes, 1969). However, previous work from this laboratory has found little support for that idea (e.g., Ayres, 1968; Ayres \& Quinsey, 1970; Hancock \& Ayres, 1974).

Also of interest is the finding that, for Group P, the difference between freezing to $T$ and $L$ was clearer on line than off line (Figure 5). Indeed, the difference was not significant off line. Some studies have found relatively small differences in freezing to $\mathrm{T}$ and $\mathrm{L}$ (e.g., Helmstetter \& Fanselow, 1989). Those relatively small modality effects may have been due to the use of an off-line situation.

For Group EU, shown on the right side of Figure 5, freezing during off-line conditioning increased slightly to $T$, remained low to $L$, and increased substantially in the pre-CS period. Group EU froze more during the pre-CS period than it did during either $\mathrm{L}$ or $\mathrm{T}[t \mathrm{~s}(7)>3.26]$. No difference was found between $T$ and $L$. Group EU appeared to freeze less to both $T$ and $L$ than did Group $P$. But the difference was significant only for $L[t(14)=2.15]$.

Figure 6 shows Group P's location during off-line conditioning. Cell 0 is missing. Its entry was sealed by a metal plate. In general, no systematic change in time spent in any area of the box occurred as training progressed, and, as usual, little time was spent in the upper half of the box. Late in training, however, the rats did spend more time in Cell 1 during $L$ than they did during $T$ or during the $2 \mathrm{~min}$ before $\mathrm{L}[t \mathrm{~s}(7)>2.51]$. The rats appeared to spend slightly less time in Cell 4 during both CSs as compared with pre-CS periods, but this trend was not significant.

Location for Group EU is not shown. No systematic changes in location occurred with training during pre-CS periods or during either CS. Like Group P, Group EU 


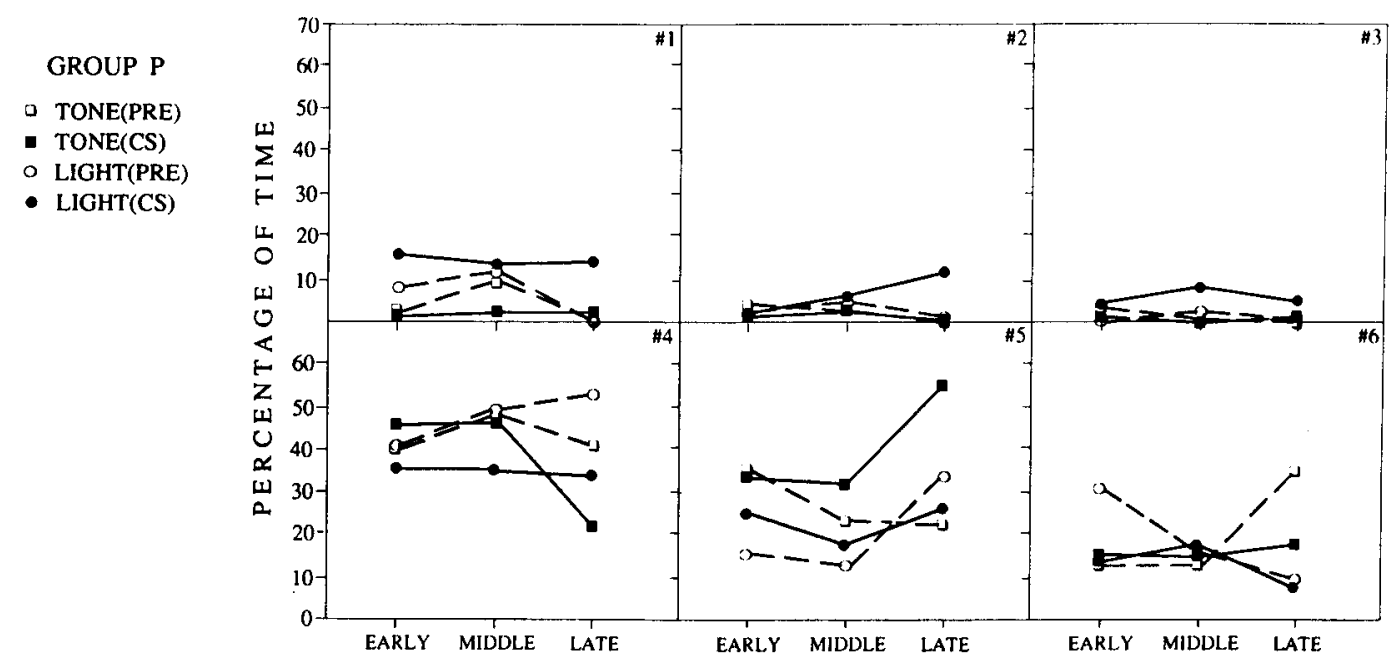

Figure 6. Time spent in given areas of the box during off-line conditioning in Experiment 2 for Group P.

spent very little time in the upper cells. Overall, the time spent in different areas of the box was similar for the two groups.

The location data obtained during off-line training are inconsistent with the hypothesis that the rat frightened by the CS simply prefers the lower middle and rear of our box. If that were true, then Group P should have spent more time in those areas during CS periods than during pre-CS periods. We found no such result in the off-line condition. We therefore seem to be left with the other possibilities discussed earlier: (1) The bar and dipper evoke behaviors (barpressing and eating) that compete with preparatory responses specific to shock. Therefore, avoiding these stimuli during CSs is reinforced by some reduction in US effectiveness. (2) The bar and dipper become aversive during CSs because the rat happens to be focused on them at the time of shock onset. (3) The behaviors of being in the bar and dipper area are adventitiously punished.

A fourth hypothesis has been suggested to us by an anonymous reviewer. The hypothesis is that rats prefer the odor of conspecifics. Moreover, this preference is increased by fear. Because rats tend to face the bar in our on-line task, they would tend to defecate mostly in the back of the box. Then, when frightened, they would prefer the back of the box because the conspecific odors would be strongest there. This preference would be less apparent during off-line conditioning because the rat would be less likely to face the bar when defecating.

There is no compelling evidence for or against any of the four hypotheses just listed. There is, however, some weak evidence against the first and the third. The first hypothesis seems to imply that the US should be more effective in on-line versus off-line procedures. In on-line procedures, the rat is less likely to be able to make preparatory responses specific to shock. We have no evidence to support that possibility. The third hypothesis seems to imply that if the rat passively avoids the behaviors of being in the bar and dipper areas, it must now be adventitiously punished for the behaviors of being in the middle and rear of the box. If so, then our location effects should be transient. Although it could be argued that we did not train long enough, we saw no evidence here for transience. The second idea does not necessarily predict transience. Even though the rat may begin spending more time in the middle and rear of the box, it may continue to focus on the bar and dipper during the CS. This hypothesis is suggested by the fact that even during CSs, rats do occasionally press the bar. Clearly, further work is needed to sort out these hypotheses. We conclude, therefore, that our location data resolve one paradox but create another. The fact that rats leave the bar and dipper area equally during tone and light CSs helps us understand how those CSs can evoke similar barpress suppression despite evoking different levels of freezing. But at the same time, the fact that rats leave the bar and dipper areas at all during CSs remains to be satisfactorily explained.

\section{REFERENCES}

ANNAU, Z., KAMIN, L. J. (1961). The conditioned emotional response as a function of intensity of the US. Journal of Comparative \& Physiological Psychology, 54, 428-432.

AYRES, J. J. B. (1968). Differentially conditioned suppression as a function of shock intensity and incentive. Joumal of Comparative \& Physiological Psychology, 66, 208-210.

Ayres, J. J. B., AXelrod, H., Mercker, E., Muchnik, F., VIGORITO, M. (1985). Concurrent observations of barpress suppression and freezing: Effects of CS modality and on-line vs. off-line training upon posttrial behavior. Animal Leaming \& Behavior, 13, 44-50.

Ayres, J. J. B., \& QUINSEY, V. L. (1970). Between-groups incentive effects on conditioned suppression. Psychonomic Science, 21, 294-296. A YRES, J. J. B., VIGoRITO, M. (1984). Posttrial effects of presenting vs. omitting expected shock USs in the conditioned suppression procedure: Concurrent measurement of barpress suppression and freezing. Animal Learning \& Behavior, 12, 73-78. 
Bevins, R. A., Ayres, J. J. B. (in press). Two issues in Pavlovian fear conditioning: Selective fear of bright vs. dark, and CS determinants of CR form. Behavioural Processes.

Bolles, R. C., Holtz, R., DunN, T., Hill, W. (1980). Comparisons of stimulus learning and response learning in a punishment situation. Leaming \& Motivation, 11, 78-96.

Bouton, M. E., Bolles, R. C. (1980). Conditioned fear assessed by freezing and by the suppression of three different baselines. Animal Learning \& Behavior, 8, 429-434.

EsTes, W. K. (1969). Outline of a theory of punishment. In B. A. Campbell \& R. M. Church (Eds.), Punishment and aversive behavior (pp. 57-82). New York: Appleton-Century-Crofts.

Estes, W. K., SkINNER, B. F. (1941). Some quantitative properties of anxiety. Journal of Experimental Psychology, 29, 390-400.

FAnsElow, M. S., \& Bolles, R. C. (1979). Naloxone and sbock-elicited freezing in the rat. Joumal of Comparative \& Physiological Psychology, 93, 736-744.

HANCOCK, R. A., AYRES, J. J. B. (1974). Within-subject effects of sucrose concentration on conditioned suppression of licking. Psychological Record, 24, 325-331.

Helmstetter, F. J., FANSELow, M. S. (1989). Differential secondorder aversive conditioning using contextual stimuli. Animal Learning \& Behavior, 17, 205-212.
Karpicke, J., Christoph, G., Peterson, G., \& Hearst, E. (1977). Signal location and positive versus negative conditioned suppression in the rat. Journal of Experimental Psychology: Animal Behavior Processes, 3, 105-118.

Sigmundi, R. A., Bouton, M. E., \& Bolles, R. C. (1980). Conditioned freezing in the rat as a function of shock intensity and CS modality. Bulletin of the Psychonomic Society, 15, 254-256.

\section{NOTE}

1. Two rats in Experiment 2 sometimes failed to barpress either during or before a CS. For one rat in Group P, this was true for tone on the early and middle 1 measures and for light on the middle 1 measure. For one rat in Group EU, it was true for tone on the middle 2 measure. In each case, the rat in question was assigned the mean suppression ratio for its group on that trial. Data points in Figure 3 reflect that estimation.

(Manuscript received May 29, 1991; revison accepted for publication November 1, 1991.) 